\title{
Prevalence and psychosocial correlates of suicidal ideation among adolescents living with HIV in Southwestern Nigeria, West Africa
}

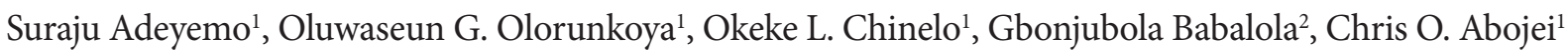 \\ ${ }^{1}$ Synapse Services, Nigeria \\ ${ }^{2}$ Federal Neuropsychiatric Hospital, Yaba, Nigeria
}

\begin{abstract}
Introduction: Adolescents with human immunodeficiency virus (HIV)/acquired immune deficiency syndrome (AIDS) have been reported to have a higher prevalence of suicidal behavior compared to those who were HIV negative. Suicidal ideation is an important comorbidity in adolescents with HIV because it has been shown to be a good predictor of both attempted and completed suicide in this group of people.

Material and methods: Participants $(n=201)$ who met the inclusion criteria were consecutively recruited from Lagos State University Teaching Hospital and the Nigerian Institute of Medical Research. Confidentiality was maintained. All the questionnaires were filled by participants, except for the MINI-Kid, which was administered by the researcher. Results were analyzed with SPSS version 20.

Results: Prevalence of current and lifetime suicidal ideation was $14.9 \%$ and $33.3 \%$ respectively. Non-disclosure $(p=0.021)$ and physical and emotional abuse $(p=0.009, p=0.020)$ were associated with lifetime suicidal ideation, while gender $(p=0.025)$, primary school $(p=0.017)$, polygamous family $(p=0.040)$, poor social support $(p=0.031)$, decline in academic performance $(p=0.005)$, loss of family member $(p=0.007)$, discrimination $(p=0.040)$, and physical and emotional abuse $(p=0.027$, $p=0.002$ ) were associated with current suicidal ideation. Only loss of family member to HIV $(p=0.003)$ was associated with current suicidal ideation after a binary logistic regression analysis.

Conclusions: Findings from this study highlight the need for clinicians to regularly assess adolescents with HIV infection for suicidal behavior, as failure to do this may further worsen the patients' condition.

HIV AIDS Rev 2019; 18, 4: 273-278

DOI: https://doi.org/10.5114/hivar.2019.85949
\end{abstract}

Key words: Nigeria, adolescents, suicidal ideation, HIV/AIDS, child abuse.

\section{Introduction}

Suicidal behavior in people living with human immunodeficiency virus (HIV)/acquired immune deficiency syndrome (AIDS) is an important health challenge globally and of great public health concern. Nigeria is considered to have

Address for correspondence: Dr. Suraju Adeyemo, Synapse Services, Nigeria, e-mail: Surajresearch@yahoo.com

the second largest number of people living with HIV worldwide, 3.2 million, with a national HIV prevalence of $2.9 \%$ in adults and 5.2\% in adolescents [1-3]. According to the World Health Organization (WHO), death as a result of suicide has increased by about $60 \%$ in the last ten years $[3,4]$. Adolescents with HIV/AIDS are more prone to suicidal behavior

Article history:

Received: 02.01.2018

Received in revised form: 23.05.2018

Accepted: 23.05.2018

Available online: 10.03.2019
International Journal of HIV-Related Problems

HIV \& AIDS

R e v i e w 
because they are faced with developmental challenges which may be seriously complicated by the burden of the further need for lifelong medication [5].

Prevalence of lifetime suicidal ideation in United Kingdom HIV clinic attendees was $31 \%$ [6]; this was similar to the prevalence of $34 \%$ reported in a Nigerian study [7] but lower than the prevalence of $44 \%$ [8] reported in a Korean study. Current suicidal ideation was reported to have a prevalence of 19\% [9] internationally, 17.1\% [10] was reported in a South African study, while $13.6 \%$ [11] was reported among people living with HIV-AIDS in west Africa and 16\% among adolescents with HIV in Nigeria [12].

Several risk factors have been reported to be associated with suicidal ideation in patients with HIV/AIDS. Some of the factors reported include younger age, female gender, poor social support, non-disclosure, non-university level of education, loss of a parent to death, family type, unstable relationship, physical abuse, sexual abuse, and emotional abuse $[6,13,14]$. Suicidal ideation is a good predictor of both attempted and completed suicide and when not identified early can lead to increased rates of morbidity and mortality $[15,16]$.

Most previous studies in sub-Saharan Africa have focused mainly on adults with HIV. There is therefore a scarcity of reports on the correlates of suicidal ideation among adolescents with HIV in this region - hence the need for the current study. The aim of this study was to determine the psychosocial and illness related correlates of both lifetime and current suicidal ideation among adolescents with HIV.

\section{Material and methods}

This was a cross sectional study. A total of 201 adolescents living with HIV-AIDS were consecutively recruited to the study from 2 facilities including the HIV out-patient clinic of Lagos State University Teaching Hospital (LASUTH), Lagos, Nigeria, and the adolescent outpatient HIV clinic of the Nigerian Institute of Medical Research (NIMR), Yaba, Lagos, Nigeria. The 2 clinics have a total of about 400 registered adolescents $($ LASUTH $=200$ and NIMR $=200)$.

\section{Participants}

The participants for this study included adolescents aged between 10 and 19 years recruited from both clinics with a confirmed laboratory diagnosis of HIV. They each gave assent to participate in the study and had written consent from their caregiver. Adolescents with other co-morbid chronic medical conditions and those who were acutely ill were excluded from the study.

\section{Study instruments}

Data were collected using the following:

1. A socio-demographic and illness variable questionnaire detailing (a) child variables such as age, gender, ethnicity, class in school (b) family variables such as parent's marital status, who the primary care giver is, family type (monogamous/ polygamous), mother's occupation, father's occupation (c) history of academic decline due to HIV-AIDS, discrimination due to HIV-AIDS and disclosure of HIV-AIDS status.

2. Social support was assessed using the "OSLO-3 item social support scale" which has a reliability of $\alpha=0.60$ and has been used by several Nigerian studies $[17,18]$.

3. Physical, emotional and sexual abuse were measured with the Adverse Childhood Experience Scale (ACE), which has concurrent validity with the Childhood Trauma Questionnaire and a reliability of $\alpha=0.80[19,20]$.

4. Lifetime and current suicidal ideation were assessed using the specific questions from the suicidality modules of the Child version of the Mini International Neuropsychiatric Interview for Children and Adolescents (MINI-KID). Studies have shown that it has a reliability in the range $\alpha=0.73-1.00[21,22]$, and it has also been used by a previous Nigerian study [22].

\section{Procedure}

\section{Ethical approval}

Ethical approval was obtained from the research ethics committees of LASUTH and NIMR. A signed consent form was taken from the parent/caregiver and verbal assent from adolescents aged less than 18 years while informed consent was taken directly from adolescents aged 18-19 years after they had been adequately informed about the study.

\section{Data collection}

All adolescents who presented to the clinic and fulfilled the eligibility criteria were consecutively recruited to the study. After consent and assent had been obtained, recruited adolescents were given the questionnaire to complete in a private consulting room before they were attended to by the clinician. While they individually completed the pre-requisites (the socio-demographic and illness variable questionnaire, OSLO-3 and the ACE), the researcher then administered the Suicidality modules of the MINI-KID. Adolescents who required help in understanding some aspects of the first part of the questionnaire were helped by the researcher. Only one researcher administered the suicidality modules of the MINI-KID to all the participants to remove inter-rater bias. The duration of the interview was about 30 minutes per participant. Recruitment continued until the sample size was reached. Participants who had suicidal ideation were psycho-educated by the researcher along with their parents or caregivers, and were referred to an adolescent-friendly mental health facility in the state where the study was conducted.

\section{Statistical analysis}

The software IBM SPSS version 20 was used to analyze all collated data. A frequency table was generated for relevant socio-demographic and illness variables in the par- 
ticipants, association between two categorical variables was determined using the $\chi^{2}$ test, while the $t$-test was used to compare mean values across groups. Binary logistic regression was used to determine variables that were independently associated with suicidal ideation.

\section{Result}

\section{Characteristics of participants}

A total of 201 adolescents with HIV infection participated in the study, with ages ranging from 10 to 19 years and mean age of 13.88 ( $\mathrm{SD} \pm 2.53$ ) years. One hundred and twenty-four (61.7\%) participants were male while 77 (38.3\%) were female. One hundred and fifty-two (75.6\%) participants were in secondary school; 76 (37.8\%) in junior secondary school and $76(37.8 \%)$ in senior secondary school, and 38 (18.9\%) and 11 (5.5\%) in primary and tertiary levels of education respectively. One hundred and thirtyseven $(68.2 \%)$ participants were from a monogamous family setting while $64(31.8 \%)$ were from a polygamous family setting. Forty-six (22.9\%) participants had history of admission on account of HIV infection, 21 (10.4\%) and 16 (8.0\%) had a decline in academic performance and relationships respectively, while 19 (9.5\%) participants had experienced discrimination due to HIV status. Forty participants (19.9\%) had strong social support, 86 (42.8\%) had moderate support while 75 (37.3\%) participants had poor social support.

\section{Prevalence of abuse and suicidal ideation among participants}

Physical abuse in childhood had the highest prevalence, $73.6 \%(n=148)$, followed by emotional abuse, $57.2 \%$ $(n=115)$, then sexual abuse, $11.4 \%(n=23)$. The lifetime prevalence of suicidal ideation in adolescents with HIV infection was $33.3 \%(n=67)$ while the prevalence rate of current suicidal ideation was $14.9 \%(\mathrm{n}=30)$ (Table 1$)$.

\section{Correlates of current suicidal ideation among participants}

There was a significantly higher rate of current suicidal ideation in participants who were female $(p=0.025)$, had primary level of education ( $p=0.017)$, from a polygamous family $(p=0.021)$, with poor social support $(p=0.031)$, with a decline in academic performance $(p=0.005)$, with loss of a family member to HIV $(p=0.007)$, and those who had been discriminated on account of their HIV status $(p=0.044)$. Similarly, participants who had been physically abused $(p=0.027)$ and those with emotional abuse $(p=0.002)$ in childhood were statistically more prone to suicidal ideation compared with those without these experiences (Table 2).

After a regression analysis, only those who had lost a family member to HIV were independently associated with current suicidal ideation. The independent variables accounted for about $42 \%$ of the variability of current suicidal ideation in adolescents with HIV infection (Table 3).
Table 1. Prevalence of childhood abuse and suicidal behavior among adolescents with HIV

\begin{tabular}{|c|c|c|}
\hline Variables & Frequency & Percentage (\%) \\
\hline \multicolumn{3}{|c|}{ Physical abuse } \\
\hline Yes & 148 & 73.6 \\
\hline No & 53 & 26.4 \\
\hline \multicolumn{3}{|c|}{ Emotional abuse } \\
\hline Yes & 115 & 57.2 \\
\hline No & 86 & 42.8 \\
\hline \multicolumn{3}{|c|}{ Sexual abuse } \\
\hline Yes & 23 & 11.4 \\
\hline No & 178 & 88.6 \\
\hline \multicolumn{3}{|c|}{ Lifetime suicidal ideation } \\
\hline Yes & 67 & 33.3 \\
\hline No & 134 & 66.7 \\
\hline \multicolumn{3}{|c|}{ Current suicidal ideation } \\
\hline Yes & 30 & 14.9 \\
\hline No & 171 & 85.1 \\
\hline
\end{tabular}

\section{Correlates of lifetime suicidal ideation among participants}

Disclosure of HIV status was associated with lifetime suicidal ideation ( $p=0.021)$; also, participants with a history of physical abuse $(p=0.009)$ and emotional abuse $(p=0.020)$ were statistically more likely to have lifetime suicidal ideation than adolescents without these experiences (Table 2). However, none of these variables were independently associated with lifetime suicidal ideation after a binary logistic regression analysis (Table 3 ).

\section{Discussion}

The prevalence of lifetime suicidal ideation among adolescents with HIV-AIDS in this study was $33.3 \%$, which is similar to findings from previous studies carried out in Nigeria (34.7\%) [23] and the UK (31.0\%) [6]. This was however lower than the prevalence (44\%) [8] reported among people living with HIV-AIDS in Korea. A possible reason for this difference may be that the Korean study was a survey. Also, the prevalence of current suicidal ideation (14.9\%) in this study was similar to findings from previous studies conducted in Western Nigeria (13.6\%) [24] and Uganda (13\%) [25]. This study further emphasizes the high prevalence of suicidal ideation in this group of adolescents.

\section{Correlates of suicidal ideation among adolescents with HIV-AIDS}

The current study shows that being female is significantly associated with a higher rate of current suicidal ideation in adolescents with HIV infection. This is in conformity with 
Table 2. Association between socio-demographic factors and current suicidal ideation $(n=201)$

\begin{tabular}{|c|c|c|c|c|c|c|}
\hline \multirow{2}{*}{ Variables } & \multicolumn{3}{|c|}{ Current suicidal ideation } & \multicolumn{3}{|c|}{ Statistics } \\
\hline & Yes, $n(\%)$ & No, $n(\%)$ & Total & $\chi^{2}$ & df & $p$ \\
\hline \multicolumn{7}{|l|}{ Current suicidal ideation } \\
\hline \multicolumn{7}{|l|}{ Gender } \\
\hline Male & $13(10.5)$ & $111(89.5)$ & 124 & \multirow[t]{2}{*}{5.029} & \multirow[t]{2}{*}{1} & \multirow[t]{2}{*}{0.025} \\
\hline Female & $17(22.1)$ & $60(77.9)$ & 77 & & & \\
\hline \multicolumn{7}{|l|}{ Level of education } \\
\hline Primary & $12(31.6)$ & $26(68.4)$ & 38 & \multirow[t]{4}{*}{1.681} & \multirow[t]{4}{*}{3} & \multirow[t]{4}{*}{0.017} \\
\hline Junior secondary school & $8(10.5)$ & $68(89.5)$ & 76 & & & \\
\hline Senior secondary school & $10(13.2)$ & $66(86.8)$ & 76 & & & \\
\hline Post-secondary school & $0(0.0)$ & $11(100.0)$ & 11 & & & \\
\hline \multicolumn{7}{|l|}{ Family type } \\
\hline Monogamous & $15(10.9)$ & $122(89.1)$ & 137 & \multirow[t]{2}{*}{5.358} & \multirow[t]{2}{*}{1} & \multirow[t]{2}{*}{0.021} \\
\hline Polygamous & $15(23.4)$ & $49(76.6)$ & 64 & & & \\
\hline \multicolumn{7}{|l|}{ Oslo score } \\
\hline Poor social support & $17(22.7)$ & $58(77.3)$ & 75 & \multirow[t]{3}{*}{6.952} & \multirow[t]{3}{*}{2} & \multirow[t]{3}{*}{0.031} \\
\hline Moderate social support & $11(12.8)$ & $75(87.2)$ & 86 & & & \\
\hline Strong social support & $2(5.0)$ & $38(95.0)$ & 40 & & & \\
\hline \multicolumn{7}{|c|}{ Decline in academic performance } \\
\hline Yes & $8(38.1)$ & $13(61.9)$ & 21 & \multirow[t]{2}{*}{9.914} & \multirow[t]{2}{*}{1} & \multirow[t]{2}{*}{0.005} \\
\hline No & $22(12.2)$ & $158(87.8)$ & 180 & & & \\
\hline Family member lost to HIV & & & & & & \\
\hline Yes & $13(27.1)$ & $35(72.9)$ & 48 & 7.341 & 1 & 0.007 \\
\hline No & $17(11.1)$ & $136(88.9)$ & 153 & & & \\
\hline Discrimination & & & & & & \\
\hline Yes & $6(31.6)$ & $13(68.4)$ & 19 & 4.583 & 1 & 0.044 \\
\hline No & $24(13.2)$ & $158(86.8)$ & 182 & & & \\
\hline Physical abuse & & & & & & \\
\hline Yes & $27(18.2)$ & $121(81.8)$ & 148 & 4.866 & 1 & 0.027 \\
\hline No & $3(5.7)$ & $50(94.3)$ & 53 & & & \\
\hline Emotional abuse & & & & & & \\
\hline Yes & $25(21.7)$ & $90(78.3)$ & 115 & 9.828 & 1 & 0.002 \\
\hline No & $5(5.8)$ & $81(94.2)$ & 86 & & & \\
\hline Correlates of lifetime suicidal & & & & & & \\
\hline Reluctant to disclose status & & & & & & \\
\hline Yes & $54(30.5)$ & $123(69.5)$ & 177 & 5.323 & 1 & 0.021 \\
\hline No & $13(54.2)$ & $11(45.8)$ & 44 & & & \\
\hline Physical abuse & & & & & & \\
\hline Yes & $57(38.5)$ & $91(61.5)$ & 148 & 6.778 & 1 & 0.009 \\
\hline No & $10(18.9)$ & $43(81.1)$ & 53 & & & \\
\hline Emotional abuse & & & & & & \\
\hline Yes & $46(40.0)$ & $69(60.0)$ & 115 & 5.376 & 1 & 0.020 \\
\hline No & $21(24.4)$ & $65(76.5)$ & 86 & & & \\
\hline
\end{tabular}

Significant $p$ value $(<0.05)$ in bold 
Table 3. Binary logistic regression of factors associated with suicidal ideation

\begin{tabular}{|c|c|c|c|c|c|c|c|c|}
\hline \multirow{2}{*}{ Variables } & \multirow{2}{*}{ B } & \multirow{2}{*}{ SE } & \multirow{2}{*}{ WALD } & \multirow{2}{*}{ df } & \multirow{2}{*}{$p$} & \multicolumn{3}{|c|}{$95 \%$ confidence interval } \\
\hline & & & & & & OR & Lower & Upper \\
\hline \multicolumn{9}{|l|}{ Current suicidal ideation } \\
\hline Gender & -0.779 & 0.493 & 2.492 & 1 & 0.114 & 0.459 & 0.174 & 1.207 \\
\hline Educational level & 20.443 & 11208.954 & 0.000 & 1 & 0.999 & 755635.8 & 0.000 & \\
\hline Family type & -0.969 & 0.503 & 3.713 & 1 & 0.054 & 0.380 & 0.142 & 1.017 \\
\hline Lost family member & 1.570 & 0.536 & 8.568 & 1 & 0.003 & 4.807 & 1.680 & 13.757 \\
\hline Academic decline & 1.059 & 0.644 & 2.706 & 1 & 0.100 & 2.884 & 0.816 & 10.185 \\
\hline Physical abuse & 0.793 & 0.848 & 0.875 & 1 & 0.350 & 2.211 & 0.416 & 11.652 \\
\hline Emotional abuse & 1.339 & 0.713 & 3.526 & 1 & 0.061 & 3.816 & 0.943 & 15.448 \\
\hline Discrimination & 0.870 & 0.747 & 1.357 & 1 & 0.244 & 2.386 & 0.552 & 10.309 \\
\hline Total Oslo score & -0.080 & 0.123 & 0.424 & 1 & 0.515 & 0.923 & 0.725 & 1.175 \\
\hline Constant & -20.939 & 11208.954 & 0.000 & 1 & 0.999 & 0.000 & & \\
\hline \multicolumn{9}{|l|}{ Lifetime suicidal ideation } \\
\hline Disclosure & -0.857 & 0.463 & 3.431 & 1 & 0.064 & 0.424 & 0.171 & 1.051 \\
\hline Physical abuse & 0.704 & 0.455 & 2.389 & 1 & 0.122 & 2.021 & 0.828 & 4.932 \\
\hline Emotional abuse & 0.325 & 0.378 & 0.738 & 1 & 0.390 & 1.383 & 0.660 & 2.900 \\
\hline Constant & -0.450 & 0.629 & 0.512 & 1 & 0.474 & 0.638 & & \\
\hline
\end{tabular}

reports from previous studies $[16,26]$ and may be due to females' tendency to internalize stressful events, as compared to males, who tend to act them out [27].

Adolescents who had poor social support were found to manifest a significantly higher rate of current suicidal ideation than those who had good social support. This is also in conformity with previous studies $[28,29]$. This highlights the importance of educating family members on the need for adequate support in the management of this group of adolescents.

There have been reports in previous studies on the influence of family type on suicidal behavior [30]. A cross-sectional study among adolescents in southwest Nigeria reported that adolescents from polygamous family settings were more likely to have suicidal ideation than those from monogamous family settings [30]. Similarly, the current study shows a significantly higher rate of suicidal ideation among participants from a polygamous family setting. People who had not disclosed their HIV status to others were more likely to have a significantly high rate of lifetime suicidal ideation than those who had disclosed their status to others; this is however contrary to findings among adult Nigerians living with HIV [31].

Data on the relationship between suicidal ideation and loss of a family member due to HIV-AIDS among adolescents living with HIV in sub-Saharan Africa are scarce. The finding in this current study, which shows a significantly higher rate of suicidal ideation among adolescents who have lost a family member to HIV, is therefore relatively new and indicates that physicians need to pay closer attention to this when managing adolescents living with HIV.
Decline in functioning may prime the mind of an individual to negative expectations regarding the outcome of their situation [32]. Conversely, good academic grades have been reported to be protective against suicidal behavior [33]. These factors may explain why there was a higher rate of suicidal ideation in participants with a decline in relationships and academic performance in this study.

\section{Association between childhood abuse and suicidal behavior}

Presence of either physical or emotional abuse has been linked with a higher rate of suicidal behavior among adolescents living with HIV [34]. Emotional abuse may affect a child's self-concept and esteem, making the child feel worthless and incapable, and subsequently such a child may develop various forms of suicidal behavior [35]. The significantly higher rate of suicidal ideation in adolescents with a history of physical and/or emotional abuse in this study therefore emphasizes the urgent need for prevention of abuse among these group of adolescents.

Sexual abuse in childhood has been reported in previous study to be associated with higher rate of suicidal ideation among adolescents in the community [30]. Contrary to this however, the current study did not show any difference in rate of suicidal ideation between adolescents with HIV who had childhood history of sexual abuse and those without such experience. Reason for this may be multifactorial and as such further research is necessary to determine the influence of sexual abuse on suicidal behavior among adolescents in 
the community compared to those with specific medical illness such as HIV infection.

\section{Conclusions}

The current study reports a high occurrence of suicidal ideation among adolescents with HIV and also identified factors that were associated with this occurrence. It can be concluded from this finding that treatment of this group of adolescents should not be limited to prescription of medications alone but should also include regular psychological assessment, psycho-education and counseling.

\section{Conflict of interest}

The authors declare no potential conflicts of interest with respect to the research, authorship, and/or publication of this article.

\section{References}

1. United Nations General Assembly. Monitoring the Declaration of Commitment on HIV/AIDS. Guidelines on Construction of Core Indicators: 2010 reporting. Available at: https://www.unaids.org/en/ resources/documents/2009/20090813_jc1676_core_indicators_manual_09_en.pdf.

2. Nwaloze RM, Frank-Peterside N, Okerentugba P. Pattern of HIV Prevalence in Tertiary Hospitals in Rivers State. Int J Novel Res Healthcare Nurs 2017; 4: 7-12.

3. Schlebusch L, Govender RD. Elevated Risk of Suicidal Ideation in HIV-Positive Persons. Depress Res Treat 2015; 2015: 1-7.

4. The Joint United Nations Programme on HIV and AIDS. Global AIDS update. 2016. Availbale at: http://www.who.int/hiv/pub/arv/ global-AIDS-update-2016_en.pdf.

5. Vreeman RC, Mccoy BM, Lee S. Review article mental health challenges among adolescents living with HIV. J Int AIDS Soc 2017; 20: 100-109.

6. Sherr L, Lampe F, Fisher M, Arthur G, Anderson J, Zetler S, et al. Suicidal ideation in UK HIV clinic attenders. AIDS 2008; 22: 1651-1658.

7. Chikezie UE, Otakpor AN, Kuteyi OB. Suicidality among individuals with HIV/AIDS in Benin City, Nigeria: a case-control study. AIDS Care 2012; 7: 843-845.

8. Kang CR, Bang JH, Cho SI, Kim KN, Lee HJ, Ryu BY, et al. Suicidal ideation and suicide attempts among human immunodeficiency virus-infected adults: differences in risk factors and their implications. AIDS Care 2016; 28: 306-313.

9. Carrico AW, Johnson MO, Morin SF, Remien RH, Charlebois ED, Steward WT, et al. Correlates of suicidal ideation among HIV-positive persons. AIDS 2007; 21: 1199-1203.

10. Govender RD, Schlebusch L. Suicidal ideation in seropositive patients seen at a South African HIV voluntary counselling and testing clinic. Afr J Psychiatry 2012; 15: 94-98.

11. Olasimbo A. Ogundipe ATO \& JDA. Suicidal Ideation among Attendees of a West African HIV Clinic. Arch Suicide Res 2015; 19: 103-116.

12. Bankole KO, Bakare MO, Edet BE, Igwe MN, Ewa AU, Bankole IA, et al. Psychological complications associated with HIV/AIDS infection among children in South-South. Cogent Med 2017; 4: 1-16.

13. Nock MK, Green JG, Hwang I, McLaughlin KA, Sampson NA, Zaslavsky AM, et al. Prevalence, correlates, and treatment of lifetime suicidal behavior among adolescents. JAMA Psychiatry 2013; 70: 300-310.

14. Johnson JG, Cohen P, Gould MS, Kasen S, Brown J, Brook JS. Childhood adversities, interpersonal difficulties, and risk for suicide attempts during late adolescence and early adulthood. Arch Gen Psychiatry 2002; 59: 741-749.
15. Govender RD, Schlebusch L. Hopelessness, depression and suicidal ideation in HIV-positive persons. South Afr J Psychiatry (Johannesburg) 2012; 18: 16-21.

16. Kinyanda E, Hoskins S, Nakku J, Nawaz S, Patel V. The prevalence and characteristics of suicidality in HIV/AIDS as seen in an African population in Entebbe district, Uganda. BMC Psychiatry 2012; 12: 63.

17. Ibrahim AW, Yahya S, Pindar SK, Wakil MA, Garkuwa A, Sale S. Prevalence and predictors of sub-optimal medication adherence among patients with severe mental illnesses in a tertiary psychiatric facility in Maiduguri, North-Eastern Nigeria. Pan Afr Med J 2015; 21: 39.

18. Abiola T, Lawal I, Habib ZG. Psychological distress due to academic stress among clinical students in a Nigerian tertiary institution: Comparison between medical and physiotherapy students. Niger J Basic Clin Sci 2015; 12: 81-85.

19. Olalekan TK. A Validation of the adverse childhood experiences scale in Nigeria. Res Hum Soc Sci 2015; 5: 18-23.

20. Oladeji BD, Makanjuola VA, Gureje O. Family-related adverse childhood experiences as risk factors for psychiatric disorders in Nigeria. Br J Psychiatry 2010; 196: 186-191.

21. Sheehan DV, Lecrubier Y, Sheehan KH, Amorim P, Janavs J, Weiller E, et al. The Mini-International Neuropsychiatric Interview (M.I.N.I.): the development and validation of a structured diagnostic psychiatric interview for DSM-IV and ICD-10. J Clin Psychiatry 1998; 59 Suppl 2: 22-33, 34-57.

22. Adeosun II. Correlates of caregiver burden among family members of patients with schizophrenia in Lagos, Nigeria. Schizophr Res Treatment 2013; 2013: 353809.

23. Chikezie UE, Otakpor AN, Kuteyi OB, James BO. Suicidality among individuals with HIV/AIDS in Benin City, Nigeria: a casecontrol study. AIDS Care 2012; 7: 843-845.

24. Oladeji BD, Taiwo B, Mosuro O, Fayemiwo SA, Abiona T, Fought AJ, et al. Suicidal behavior and associations with quality of life among HIV/AIDS-infected patients in Ibadan, Nigeria. J Int Assoc Provid AIDS Care 2017; 16: 376-382.

25. Petrushkin A, Boardman J, Ovuga E. Psychiatric disorders in HIVpositive individuals in urban Uganda. Psychiatr Bull 2005; 29: 455-458.

26. Miret M, Caballero FF, Huerta-Ramírez R, Moneta MV, Olaya B, Chatterji $\mathrm{S}$, et al. Factors associated with suicidal ideation and attempts in Spain for different age groups. Prevalence before and after the onset of the economic crisis. J Affect Disord 2014; 163: 1-9.

27. Shilagh M. Stress and Gender: Common Triggers and How to Cope. Uwhealth, 2015. Available at: https://www.uwhealth.org/news/stressand-gender-the-differences-in-coping/44728.

28. Nock MK, Borges G, Bromet EJ, Alonso J, Angermeyer M, Beautrais $\mathrm{A}$, et al. Cross-national prevalence and risk factor for suicidal ideation, plans, and attempts. Br J Psychiatry 2008; 192: 98-105.

29. Casey PR, Dunn G, Kelly BD, Birkbeck G, Dalgard OS, Lehtinen V, et al. Factors associated with suicidal ideation in the general population: five-centre analysis from the ODIN study. Br J Psychiatry 2006; 189: 410-415.

30. Omigbodun O, Dogra N, Esan O, Adedokun B. Prevalence and correlate of suicidal behavour among adolescent in southwest Nigeria. Int J Soc Psychiatry 2008; 54: 34-46.

31. Ogundipe OA, Olagunju AT, Adeyemi JD. Suicidal ideation among attendees of a West African HIV clinic. Arch Suicide Res 2015; 19: 103-116.

32. McIntosh CN, Fischer DG. Beck's cognitive triad: one versus three factors. Can J Behav Sci 2000; 32: 153-157.

33. Gould MS, Greenberg T, Velting DM, Shaffer D. Youth suicide risk and preventive interventions: a review of the past 10 years. J Am Acad Child Adolesc Psychiatry 2003; 42: 386-405.

34. Jewkes RK, Dunkle K, Nduna M, Jama PN, Puren A. Associations between childhood adversity and depression, substance abuse and HIV and HSV2 incident infections in rural South African youth. Child Abuse Negl 2010; 34: 833-841.

35. Khartri K. Child Abuse, Definition, Prevention, Types, Treatment, Maltreatments Articles, Children's Abuse. 2004. Available at: http:// www.umicos.umd.edu/users/sawweb/sawnet/childabuse.html. 